\title{
Readers respond
}

\section{Correspondence}

\section{Sahel crisis: cut global emissions}

The recommendations by Alisha Graves and her colleagues for averting catastrophe in Africa's Sahel overlook the need to address the drivers of its climate and ecological crises (Nature 575, 282-286; 2019).

Although the authors' recommendations could help to prevent catastrophe in the short to medium term, immediate action is also needed against the fundamental causes if we are to mitigate crises of rapidly escalating scale and severity in the longer term.

This might seem obvious, but it must be emphasized repeatedly if we are to ramp up our currently woefully inadequate action against the global climate and ecological emergency. Otherwise, there is an implicit acceptance of the status quo and the current trajectory. And the catastrophe in the Sahel, and others like it around the world, will not be averted, but at best delayed.

Keir Philip Imperial College London, UK.

k.philip@imperial.ac.uk 